\title{
Elucidating the Value of Continuous Brain Oxygen Monitoring
}

\author{
Alejandro A. Rabinstein
}

Received: 16 July 2009/Accepted: 24 July 2009/Published online: 6 August 2009

(C) Humana Press Inc. 2009

The use of invasive multimodality monitoring in comatose patients, particularly those with severe traumatic brain injury (TBI) and poor-grade subarachnoid hemorrhage, is one of the most debated topics among neurocritical care specialists today. Proponents and skeptics have valid arguments. Proponents argue that the rationale for the application of new technologies to assess brain oxygenation and metabolism is solid. Others remain skeptic because there is very limited clinical data showing that these monitoring techniques can improve patient outcome.

Several modalities are available, but just a few are used in NICUs with certain frequency. Jugular bulb catheters allow measurement of the difference between arterial and venous oxygen saturation, thus estimating global oxygen demand. Although useful, this method does not indicate actual brain oxygenation and technical difficulties are not uncommon (such as apposition of the catheter against the venous wall). Microdialysis offers a wealth of information about local-some would contend regional-brain metabolism and permits recognition of instances of energy failure. However, it is very labor-intensive and requires considerable expertise. Brain tissue oxygen monitoring $\left(\mathrm{BtO}_{2}\right.$ or $\left.\mathrm{PtiO}_{2}\right)$ using the Licox system directly measures partial pressure of oxygen in brain tissue. Licox catheters are simple to use; they are pre-calibrated and only require a period of stabilization after insertion (usually 30-90 min) after which they can provide steady readings for up to several days. Normal values $(25-30 \mathrm{mmHg})$ and a cut-off for brain hypoxia $(<10 \mathrm{mmHg})$ have been well defined.

A. A. Rabinstein $(\square)$

Division of Critical Care Neurology-Department of Neurology,

Mayo Clinic College of Medicine, 200 First Street SW,

Rochester, MN 55905, USA

e-mail: rabinstein.alejandro@mayo.edu
Insertion is usually quite safe. Yet, only some NICUs use Licox catheters consistently while many others-including ours-await proof that their use has a beneficial impact on patient care and outcomes before they incorporate them into their practices.

A systematic review reported by the group of prolific investigators from the University of Pennsylvania examines the available evidence regarding the effect of $\mathrm{BtO}_{2}$ on clinical outcome after severe TBI [1]. The authors evaluated the literature rigorously and finally identified only three observational studies with sufficient information to warrant inclusion in their analysis [2-4]. The resulting combined population consisted of 150 patients monitored with $\mathrm{BtO}_{2}$ for 1-7 days. Episodes of brain hypoxia were defined as $\mathrm{BtO}_{2}<10 \mathrm{mmHg}$ for $>15 \mathrm{~min}$. Odds ratios of mortality and poor functional outcome (Glasgow outcome score 1-3) at 6 months were four times greater in patients with episodes of brain hypoxia. In their review of published studies, the authors only identified two complications resulting from insertion of the brain oxygen monitoring catheter among 292 patients eligible for this safety analysis, and both of these complications were inconsequential hemorrhages [1].

Although promising, the data analyzed and presented in this review can only be considered preliminary. The contention by the authors of the review that the use of intracranial pressure monitors is considered standard of care for severe TBI patients despite never having been proven to reduce morbidity or mortality in randomized, controlled trials is fair. Yet, when we look at intracranial pressure and cerebral perfusion pressure measurements we know exactly what they mean, while we are still learning about the significance of brain oxygen tension as measured by the Licox system. Studies have reported that brain hypoxic episodes identified by the Licox system may occur 
despite controlled intracranial pressure and adequate cerebral perfusion pressure [5]. But what is exactly $\mathrm{BtO}_{2}$ telling us? Most recent data suggest that it may be an indicator of the diffusion of dissolved plasma oxygen across the blood-brain barrier (oxygen diffusion defined as the product of cerebral blood flow and arteriovenous oxygen tension difference) at the local/regional level rather than a direct measure of cerebral blood flow, total oxygen delivery, or brain metabolism [6].

In their thoughtful discussion, the authors of the systematic review correctly point out several lingering questions regarding the value and appropriate use of $\mathrm{BtO}_{2}$ monitoring [1]. These include what is the critical threshold of brain hypoxia above which outcome is irreversibly worsened (available studies do not provide sufficient detail on the number and duration of the hypoxic episodes making it impossible to calculate the hypoxic burden), what are the optimal treatment adjustments that should be prompted by low $\mathrm{BtO}_{2}$ measurements, and whether $\mathrm{BtO}_{2}$ monitoring is actually a cost-effective intervention. I would also question whether $\mathrm{BtO}_{2}$ monitoring can be used in isolation or needs to be combined with other more global modalities, such as jugular venous oxymetry, given the fact that brain damage in TBI is far from uniform and local/ regional measures may thus be insufficiently representative of the severity of the entire disease process.

Several top-quality NICUs in USA and Europe have accumulated substantial experience with $\mathrm{BtO}_{2}$ monitoring.
Those of us waiting on the sidelines for more definitive information on the value of this intervention would greatly benefit from the conduction of a large multi-center study designed to answer those remaining questions.

\section{References}

1. Maloney-Wilensky E, Gracias V, Itkin A, Hoffman K, Bloom S, Yang W, et al. Brain tissue oxygen and outcome after severe traumatic brain injury: a systematic review. Crit Care Med. 2009;37(6):2057-63.

2. Bardt TF, Unterberg AW, Härtl R, Kiening KL, Schneider GH, Lanksch WR. Monitoring of brain tissue PO2 in traumatic brain injury: effect of cerebral hypoxia on outcome. Acta Neurochir Suppl. 1998;71:153-6.

3. van den Brink WA, van Santbrink H, Steyerberg EW, Avezaat CJ, Suazo JA, Hogesteeger C, et al. Brain oxygen tension in severe head injury. Neurosurgery. 2000;46(4):868-76.

4. Kiening KL, Härtl R, Unterberg AW, Schneider GH, Bardt T, Lanksch WR. Brain tissue pO2-monitoring in comatose patients: implications for therapy. Neurol Res. 1997;19(3):233-40.

5. Stiefel MF, Udoetuk JD, Spiotta AM, Gracias VH, Goldberg A, Maloney-Wilensky E, et al. Conventional neurocritical care and cerebral oxygenation after traumatic brain injury. J Neurosurg. 2006;105(4):568-75.

6. Rosenthal G, Hemphill JC 3rd, Sorani M, Martin C, Morabito D, Obrist WD, et al. Brain tissue oxygen tension is more indicative of oxygen diffusion than oxygen delivery and metabolism in patients with traumatic brain injury. Crit Care Med. 2008;36(6):1917-24. 